\title{
Physiological Role of FGF Signaling in Growth and Remodeling of Developing Cardiovascular System
}

\author{
E. KREJCI ${ }^{1,2}$, Z. PESEVSKI ${ }^{1,2}$, O. NANKA ${ }^{1}$, D. SEDMERA ${ }^{1,2}$ \\ ${ }^{1}$ Institute of Anatomy, First Faculty of Medicine, Charles University in Prague, Prague, Czech \\ Republic, ${ }^{2}$ Institute of Physiology of the Czech Academy of Sciences, Prague, Czech Republic
}

Received October 7, 2015

Accepted January 15, 2016

On-line April 12, 2016

\section{Summary}

Fibroblast growth factor (FGF) signaling plays an important role during embryonic induction and patterning, as well as in modulating proliferative and hypertrophic growth in fetal and adult organs. Hemodynamically induced stretching is a powerful physiological stimulus for embryonic myocyte proliferation. The aim of this study was to assess the effect of FGF2 signaling on growth and vascularization of chick embryonic ventricular wall and its involvement in transmission of mechanical stretchinduced signaling to myocyte growth in vivo. Myocyte proliferation was significantly higher at the $48 \mathrm{~h}$ sampling interval in pressure-overloaded hearts. Neither Western blotting, nor immunohistochemistry performed on serial paraffin sections revealed any changes in the amount of myocardial FGF2 at that time point. ELISA showed a significant increase of FGF2 in the serum. Increased amount of FGF2 mRNA in the heart was confirmed by real time PCR. Blocking of FGF signaling by SU5402 led to decreased myocyte proliferation, hemorrhages in the areas of developing vasculature in epicardium and digit tips. FGF2 synthesis is increased in embryonic ventricular cardiomyocytes in response to increased stretch due to pressure overload. Inhibition of FGF signaling impacts also vasculogenesis, pointing to partial functional redundancy in paracrine control of cell proliferation in the developing heart.

\section{Key words}

Chick embryo • Vasculogenesis • FGF2 • FGFR1 • Myocyte proliferation • Conotruncal banding • SU5402

\section{Corresponding author}

D. Sedmera, Institute of Physiology of the Czech Academy of Sciences, Videnska 1083, 14220 Prague 4, Czech Republic. E-mail: dsedmera@biomed.cas.cz

\section{Introduction}

Fibroblast growth factor (FGF) signaling plays an important role in development and homeostasis of many tissues. To date, 23 FGFs have been identified in organisms ranging from nematodes to humans. The various factors vary in size from 17 to $34 \mathrm{kDa}$ in vertebrates, and up to $84 \mathrm{kDa}$ in Drosophila. Members of the human family share a high affinity for heparin and heparin sulfate proteoglycans, as well as between 30 and $60 \%$ homology within a central core domain of 120 amino acids. This central core folds into twelve antiparallel $\beta$-strands arranged into a triangular array necessary for receptor interaction. FGFs are widely expressed in developing and adult tissues. The biological activities of FGF include roles in cellular proliferation, differentiation, and migration during embryonic development and tissue repair, wound healing, and tumor angiogenesis (de Almeida and Sedmera 2009).

Multiple studies, both in vivo and in vitro, agree on a pivotal role of the $\mathrm{FGF} / \mathrm{FGF}$ receptor (FGFR) cascade in immature myocytes (Speir et al. 1992, Sugi et al. 1993, Kardami et al. 1995, Mima et al. 1995, Lavine et al. 2005). The FGFs bind to FGFRs located on the cell surface. These receptors are members of the receptor tyrosine kinase superfamily. Among 23 members of the FGF family and 4 different FGF receptors, FGF1 and 2 
and FGFR1 are the ones most frequently implicated, although other FGFs, such as FGF8 (Farrell et al. 2001) and FGF10 (Kelly et al. 2001) also play an important role in cardiac development. We have shown recently that exogenous addition of depleted FGF2 can rescue myocyte proliferation in the context of experimental left ventricular hypoplasia, indicating the therapeutic potential of soluble factors controlling myocyte proliferation (de Almeida and Sedmera 2009). Growth factors may be produced by myocytes themselves and released in response to increased stretch (Clarke et al. 1995). The epicardium is often cited as a source of signaling molecules modulating myocyte proliferation such as PDGF (Kang et al. 2008) or retinoic acid (Chen et al. 2002). To test the possible role of other growth factors, we analyzed also the expression of PDGFA and $\mathrm{B}$ and the appropriate receptors by methods outlined in our previous study (Sedmera et al. 2002) and by RT-PCR.

FGF2 can be produced by cardiac myocytes and non-myocytes. The exact secretion mechanism is not entirely clear, but it was suggested that its phosphorylation might be involved in its unconventional (Golgi- and endoplasmatic reticulum-independent) transport (Ebert et al. 2010). Once outside the cell, it shows strong binding to molecules of extracellular matrix such as heparin sulphate proteoglycans, and more recently discovered specific FGF binding proteins (Gibby et al. 2009). It may act, therefore, in a paracrine or autocrine fashion in the heart. During the phase of rapid growth through hyperplasia, FGF2, FGF9, FGFR1 are the only fibroblast growth factors and receptors that were shown to be expressed in mouse and chick ventricles (Pennisi et al. 2003, Lavine et al. 2008). Expression patterns of FGF in general correlate with their role in proliferation and morphogenesis (Mikawa 1995, Kelly et al. 2001).

Currently available array of inhibition studies of FGF signaling includes neutralizing antibodies to FGF2 (Sheikh et al. 1999, Tomanek et al. 2008), its major receptor (Sugi et al. 1995, Zhu et al. 1999), chemical receptor interaction inhibition by sodium chlorate (Zhu et al. 1999), and more recently, specific inhibition of receptor-associated tyrosine kinase by SU5402 (Demiroglu et al. 2001, Marques et al. 2008). Other alternatives include a dominant negative FGF receptor (Sato et al. 2011), ligand-binding domain of FGFR, and RNA interference (Torlopp et al. 2011, Vega-Hernandez et al. 2011). These studies have invariably documented critical role of FGF-mediated signaling in various situations. Conflicting results were obtained in mouse using various knockout strains. Deletion of FGF2 results in no apparent phenotype (Zhou et al. 1998), but there was demonstrated abnormal regulation of vascular tone in the adults. On the other hand, deletion of FGF8 (Lavine et al. 2008) resulted in embryonic ventricular hypoplasia, and an even stronger phenotype was obtained by double (but not single) deletion of FGFR1 and 2.

Embryonic pressure overload model was created in the chick embryo by the means of conotruncal banding (Clark et al. 1989), and was used to study changes in myocardial architecture (Sedmera et al. 1999b, Tobita et al. 2005) and coronary development (Tomanek et al. 1999). It results in purely hyperplastic myocardial growth, accelerated myocardial morphogenesis and proportionally increased angiogenesis to match the demands of thickening ventricular wall.

In this study, the physiological role of FGF2 signaling during embryonic myocardial growth and differentiation in vivo was explored to provide a better understanding about the role of FGF2/FGFR1 signaling during mid-gestation cardiovascular development. It was hypothesized that growth induced by means of experimentally created pressure overload would be accompanied by its upregulation while inhibition of this cascade would lead to decreased myocardial proliferation. Pressure overload led, surprisingly, to a decrease in the amount of FGF2 protein in the myocardium, accompanied by its increase in the serum; however, increased myocardial synthesis at the mRNA level was demonstrated by RT-PCR. Pharmacological inhibition of FGFR1 led at an early stage to decreased myocyte proliferation, and later to myocardial dysmorphogenesis with blood leakage through the ventricular wall and hemorrhages into developing digits, indicating differential requirements of this growth factor by the developing cardiovascular system.

\section{Material and Methods}

\section{Conotruncal banding}

White Leghorn chicken eggs were incubated in a forced-draft humidified incubator at $38^{\circ} \mathrm{C}$. Pressure overload was induced in ED3 chick embryos by means of placing a snug, but non-constricting ligature around the conotruncus (Fig. 1) as described in detail previously (Clark et al. 1989, Sedmera et al. 1999b). Control eggs were windowed, exposed, and the suture was passed 
under the conotruncus and removed. Sampling was performed at 24, 48, and $72 \mathrm{~h}$ at ED4, 5, and 6 . The embryos were labeled with $50 \mu \mathrm{g}$ of 5'-bromodeoxyuridine (Sigma) one hour prior to sampling (Sedmera et al. 1999a). The embryos were fixed in $4 \%$ paraformaldehyde in PBS and processed for paraffin sectioning ( $n=6$ per stage, per group). Blood was collected from ED5 embryos via puncture of the dorsal aorta using a bent, sharpened glass micropipette connected to mouthpiece that was used for perfusion fixation of the embryonic hearts (Sedmera et al. 1997). Samples were pooled from 3 embryos and frozen until further processing.
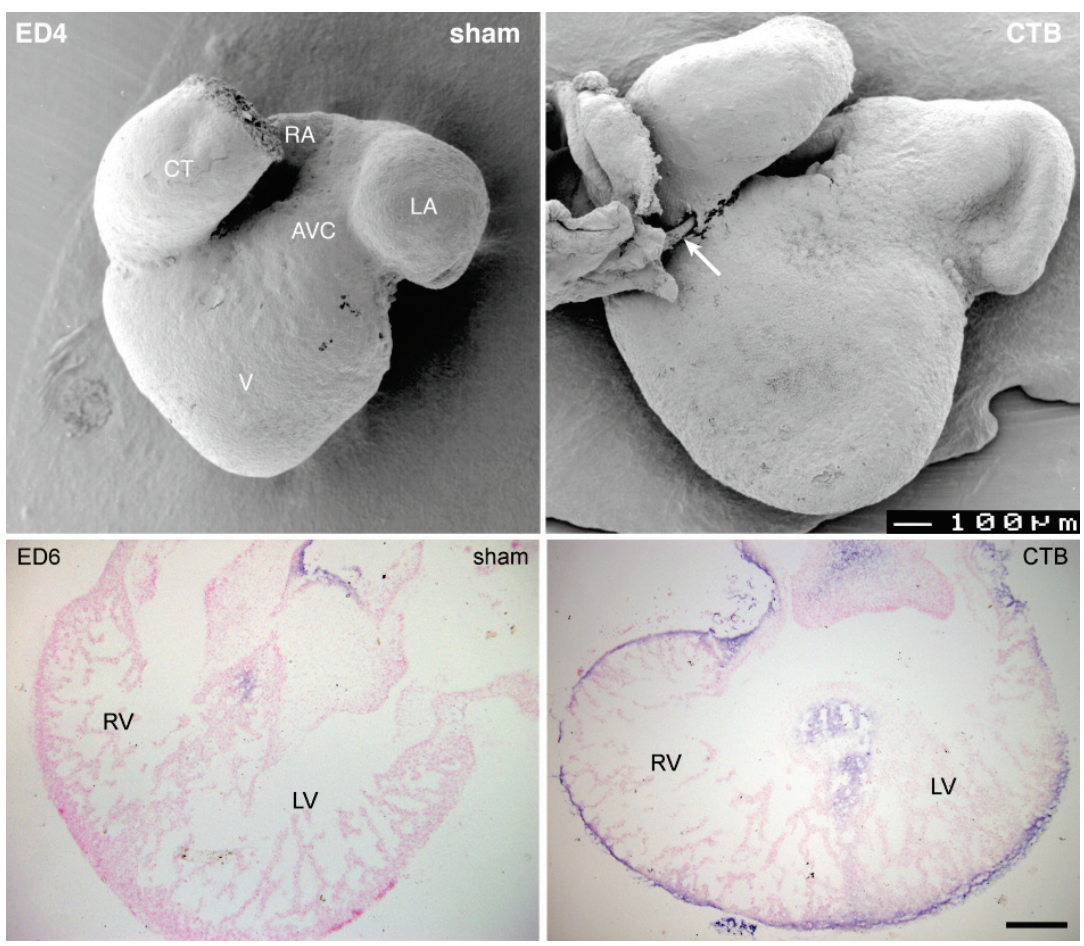

Fig. 1. Scanning electron micrographs showing phenotype at $24 \mathrm{~h}$ after conotruncal banding (ED4). The banded heart is enlarged, and the ventriculo-conotruncal fold is attached to a piece of body wall by the ligature (arrow). AVC, atrioventricular canal; $C T$, conotruncus; LA, left atrium; RA, right atrium; V, ventricle. Sham-operated heart (left) shows now difference from intact controls (not shown). Bottom panels show the results of hypoxyprobe staining. Considerable increase in the extant of hypoxic zones, normally confined to the muscular part of the interventricular septum (control, left panel), is observed in the banded embryo 3 days after procedure (CTB, right panel). Scale bar $100 \mu \mathrm{m}$.

\section{Inhibition of FGF signaling}

At ED4, two groups of ten embryos each received SU5402 diluted first in DMSO to $4.166 \mathrm{mM}$ concentration, and then to $\mathrm{dH}_{2} \mathrm{O}$ to achieve final volume of $100 \mu \mathrm{l}$ per embryo. This cell-permeable inhibitor of tyrosine kinase of FGFR1 (IC50=10-20 $\mu \mathrm{M}$ ) also inhibits phosphorylation of ERK1 and ERK2, mediated by FGF1; however, it has only a weak inhibitory potential for the PDGF receptor, and has no effects on insulin receptor and EGF receptor kinase. Working solution was then injected intraamniotically at doses of 12.5 and $37.5 \mu \mathrm{g}$ per embryo; controls $(n=15)$ received equal volume of $20 \%$ DMSO in $\mathrm{dH}_{2} \mathrm{O}$. For more targeted intrathoracic application, $0.5 \mu \mathrm{l}$ of DMSO solution containing $6.25 \mu \mathrm{g}$ SU5402 was injected with a glass needle ( $n=6$ vehicle control and 9 experimental embryos). For inhibition at ED8, 24 embryos were injected with $25 \mu \mathrm{g}$ of SU5402 prepared as above; 13 controls received the same volume of the solvent. In both cases, sampling was $24 \mathrm{~h}$ after injection, preceded by labeling with $50 \mu \mathrm{g}$ of 5'-bromodeoxyuridine one hour prior to sacrifice, as described above.

\section{Histology and immunohistochemistry}

After serial sectioning at $8 \mu \mathrm{m}$, alternate sections in $40 \mu \mathrm{m}$ intervals were mounted on glass slides and stained with hematoxylin and eosine (guide series). Sections containing ventricular midportion were then selected and stained with antibodies against FGF2 (1:100, Santa Cruz Biotechnology, sc-79) (Sedmera et al. 2002) or 5'-bromodeoxyuridine (1:100, Becton Dickinson) (Sedmera et al. 1999a). Primary antibodies were detected with fluorescently labeled appropriate secondary antibodies (goat anti-rabbit coupled with Cy3, Jackson Immuno, for anti-FGF2 and donkey anti-mouse coupled with Alexa488, Molecular Probes, for antibromodeoxyuridine, respectively). The sections were counterstained with nuclear dye Hoechst 33342, coverslipped, and examined under a Leica SP2 confocal microscope. Quantification of fluorescent labeling was 
performed as described (Sedmera et al. 2002) using appropriate sets of controls (i.e. background subtraction after omission of primary antibody). Hypoxyprobe staining to detect regions of tissue hypoxia was performed as described in detail previously (Nanka et al. 2006, 2008).

\section{Western blotting}

Five hearts per group were pooled at $24 \mathrm{~h}$ sampling interval after conotruncal banding (ED4) to obtain sufficient amount of tissue for Western blotting. Processing and quantification was performed exactly as described (Sedmera et al. 1999a) on two such pools per group (sham and banded hearts).

\section{ELISA}

Blood samples (five pools from each embryo each per group, sampled at the 48 sampling interval) were diluted in the dilution buffer. Total protein concentration was estimated using BSA as a standard. Quantification of FGF2 amounts was performed using FGF2 ELISA kit from R\&D Systems (Cat. \# DFB50) per manufacturer's instructions.

\section{$R T-P C R$}

Each sample of banded or sham operated hearts (initially five pools of three hearts each, later individual hearts, $N \geq 6$ ) or the rest of the embryos was rapidly freezed in liquid nitrogen. RNA was isolated using RNeasy Micro Kit (Qiagen) and reverse transcription was performed using AccuScript High Fidelity 1st Strand cDNA Synthesis Kit (Agilent) according to manufacturer's instructions. Control samples prepared in the same way as cDNA but without reverse transcriptase were used to exclude RNA or non-specific amplification. Gene Expression Analysis Taqman Assays for chicken FGF2, PDGFA and GAPDH and TaqMan Gene Expression Master Mix were used for qPCR on 7900HT Fast Real-Time PCR System (https://products.appliedbiosystems.com/ab/en/US/adir ect $/ \mathrm{ab}$ ?cmd=catNavigate $2 \&$ catID $=601255$, all from Life Technologies). Acquired data were statistically analyzed using REST2009 software (Qiagen).

\section{Statistics}

Results between groups were compared using unpaired Student's t-test after normality of data distribution was confirmed. $\mathrm{P}$ values of $<0.05$ were considered significant. RT-PCR data were analyzed using bundled software (Qiagen).

\section{Results}

Increased myocyte proliferation after conotruncal banding is partly mediated by increased FGF2 synthesis

Phenotype of hearts subjected to snug banding of the conotruncus (initially non-constricting, with gradual development of stenosis) is illustrated in a scanning electron micrograph (Fig. 1) in ED4 hearts. There is initially heart dilation, resulting in increased chamber dimensions with more spherical shape, followed later by compact layer thickening (Sedmera et al. 1999b), trabecular spiraling and increased myocyte proliferation over prolonged time period (Sedmera et al. 2005). Interestingly, thickening of the myocardium in response to pressure overload leads to an increase in the extent of hypoxic regions (Fig. 1), as the coronary vasculature is not functional until ED9 and often develops abnormally in this model (Tomanek et al. 1999). This type of constriction was chosen because it results in better mid-term survival (Fig. 2) than immediate lumen restriction, which becomes quickly limiting for embryonic growth and cardiac output. With this approach, maximal adaptive changes based upon increased proliferation were detected at $48 \mathrm{~h}$ after constriction (Fig. 2). It was attempted to correlate these changes in proliferative structure with longitudinal assessment of myocardial FGF2 levels. Within the heart, there is a gradient of expression within the ventricular wall correlating with the proliferative activity (Mikawa 1995, Sedmera et al. 2002). Therefore, the levels of FGF2 were measured in the compact layer of the ventricle, an area expected to react most readily to experimental challenges by altered growth factor expression and proliferation rate (Sedmera et al. 2002). Surprisingly, there was initially no change, but at $48 \mathrm{~h}$ and $72 \mathrm{~h}$ time intervals there was a significant decrease in the left ventricle, followed by a similar drop (62\%) in the right ventricle at $72 \mathrm{~h}$ (Supplemental Fig. 1). Immunohistochemical data was verified using an established protocol (Sedmera et al. 1999a) by Western blotting at the $24 \mathrm{~h}$ interval, where there was indeed no change against controls (data not shown). As it was shown to be released from the myocytes upon stretching (Clarke et al. 1995, Aranega et al. 1998), we searched for the FGF2 protein in the blood. Using ELISA FGF2 assay in the serum samples, almost double concentration of the protein in the banded embryos was found (Fig. 3). 


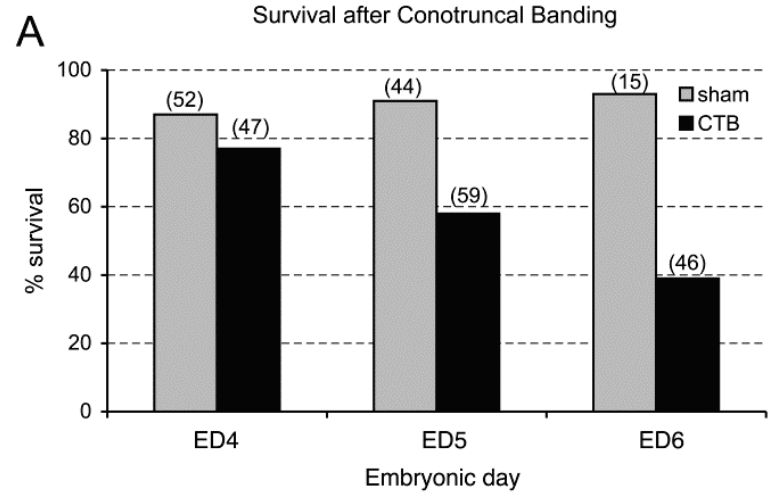

B Left ventricular myocyte proliferation

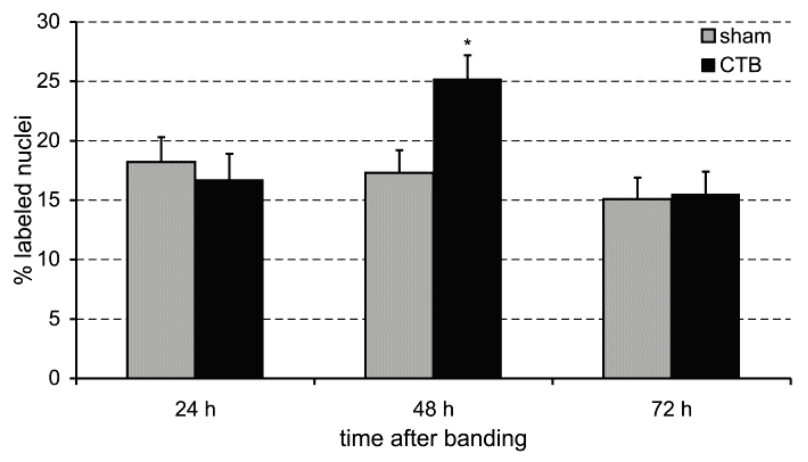

C

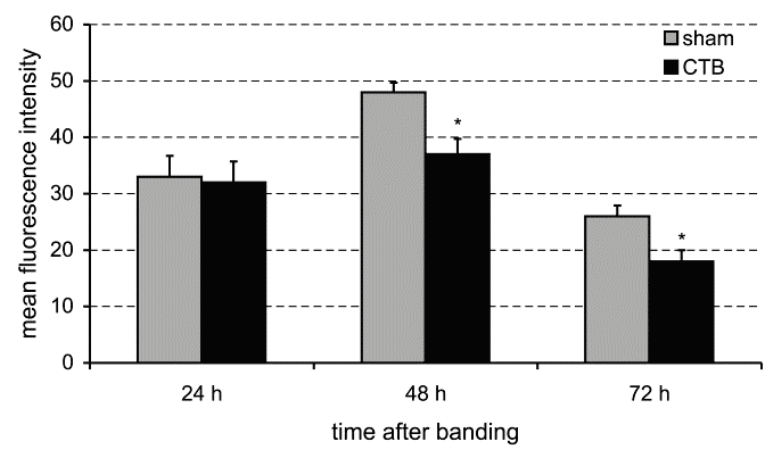

Fig. 2. Graphs showing embryo survival (A), proliferation assessed by 2-h pulse-labeling with $5^{\prime}$-bromodeoxyuridine in the left ventricular compact zone (B) after conotruncal banding ( $\mathrm{N}=6$ per group, per stage), and FGF2 expression detected by immunohistochemistry in the left ventricular compact zone $(\mathrm{N}=6$ per group, per stage). Embryonic days (ED) 4, 5, and 6 correspond to 24, 48, and $72 \mathrm{~h}$ sampling intervals after banding. Data are mean $\pm \mathrm{SD}, * \mathrm{p}<0.05$, values in parentheses indicate the total number of embryos sampled at each stage (pooled from all experiments). For proliferation study, $\mathrm{N}=6$ per stage, per group.

To verify the myocardial origin of this protein, RT-PCR was performed on ventricular samples from the hearts $48 \mathrm{~h}$ after conotruncal banding. Indeed, there was a significant increase in the amount of FGF2 mRNA (1.476x, p=0.023, Fig. 3). Repeated experiment confirmed this increase $(1.693 \mathrm{x}, \mathrm{p}=0.034)$, and simultaneously excluded other embryonic tissues as a significant source of increased serum FGF2 levels (1.031x, $\mathrm{p}=0.764)$. Interestingly, a weak increase in expression $(1.467 \mathrm{x}, \mathrm{p}=0.026)$ was observed in the heart already at the $36 \mathrm{~h}$ sampling point $(1.423, \mathrm{p}=0.001)$, at which stage there was also an increase in the extracardiac tissues. To probe for alternative growth factors mediating loading-induced proliferation, we performed also RT-PCR reaction for PDGFA, which was suggested as another candidate (Jedlicka et al. 1991, Kang et al. 2008). There was a significant increase at the $36 \mathrm{~h}$ in the heart (1.816x, $\mathrm{p}=0.014)$ as well as the rest of the embryo (1.436x, $\mathrm{p}=0.016)$, but there were no differences at the $48 \mathrm{~h}$ time point (data not shown).
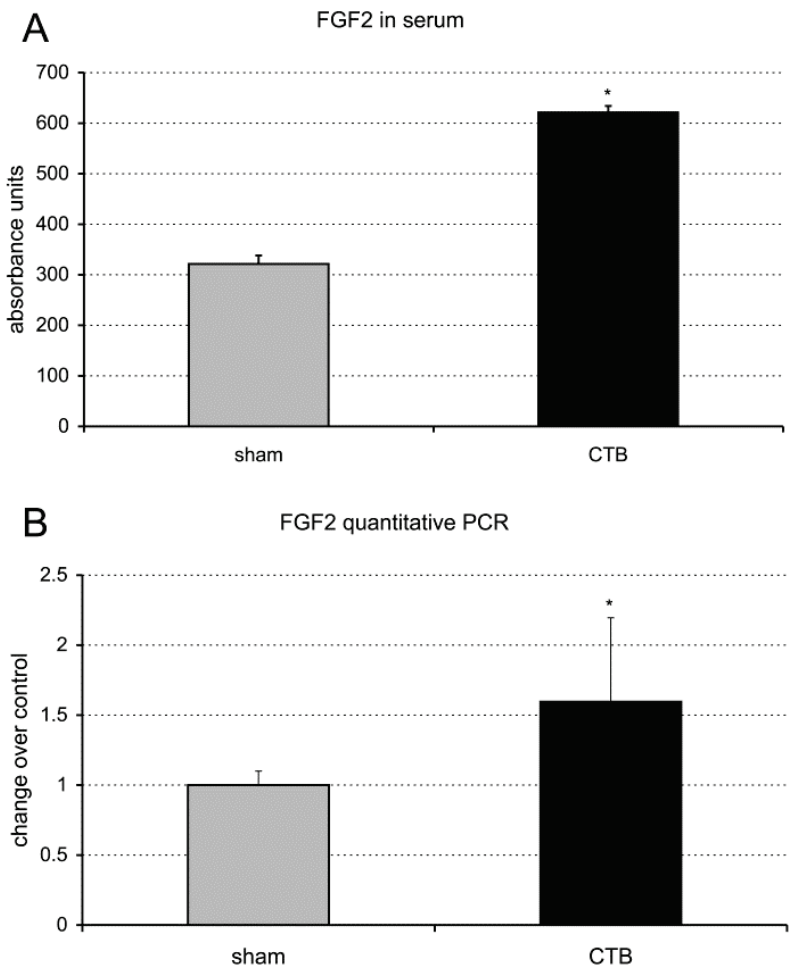

Fig. 3. A. ELISA assay showing an increased amount of FGF2 protein in serum at $48 \mathrm{~h}$ (ED5) after conotruncal banding. Values are means \pm SD from 5 pools of 3 embryos, assayed in triplicate. B. RT-PCR data showing increased amount of FGF2 mRNA in ventricles at the same stage. Data are mean $\pm S D, N=5$ pools of 3 hearts per group.

Inhibition of FGF signaling impairs myocyte proliferation and vascular development

FGF2 is expressed in the developing chick in multiple tissues including the limbs, heart, somites, epithelia, and lungs. To characterize its functional role in embryogenesis, in vivo inhibition of FGF signaling was performed via blocking the tyrosine kinase associated with FGFR1 by SU5402. Administration of this inhibitor 
at ED4 resulted in very high mortality (survival at ED5: $0 / 10$ with the dose of $37.5 \mu \mathrm{g}$ per embryo, and $2 / 10$ with $12.5 \mu \mathrm{g}$ dose) with intraamniotic application. More targeted intrathoracic application was then used, resulting in acceptable survival rates (67\% with the $6.25 \mu \mathrm{g}$ dose, vehicle controls $100 \%$ ), and a significant (29\%) decrease in myocyte proliferation after $24 \mathrm{~h}$ at ED5 (Fig. 4). No malformations were observed in the surviving embryos. Systemic administration at ED8 was better tolerated with $24-\mathrm{h}$ survival rate of $50 \%$ with
$25 \mu \mathrm{g}$ dose administered intraamniotically. The surviving embryos presented with hemorrhages in the limb tips (10/12 cases, Supplemental Fig. 2), and subepicardial hemorrhage (3/12, Fig. 4). Analysis of cell proliferation detected a small, non-significant drop in the heart, but a very strong $79 \% \quad(p=0.01) \quad$ decrease in the perichondrium (Supplemental Fig. 2). Using the standard post-mortem examination protocol (Jelinek et al. 1985), no malformation in the other systems were detected.
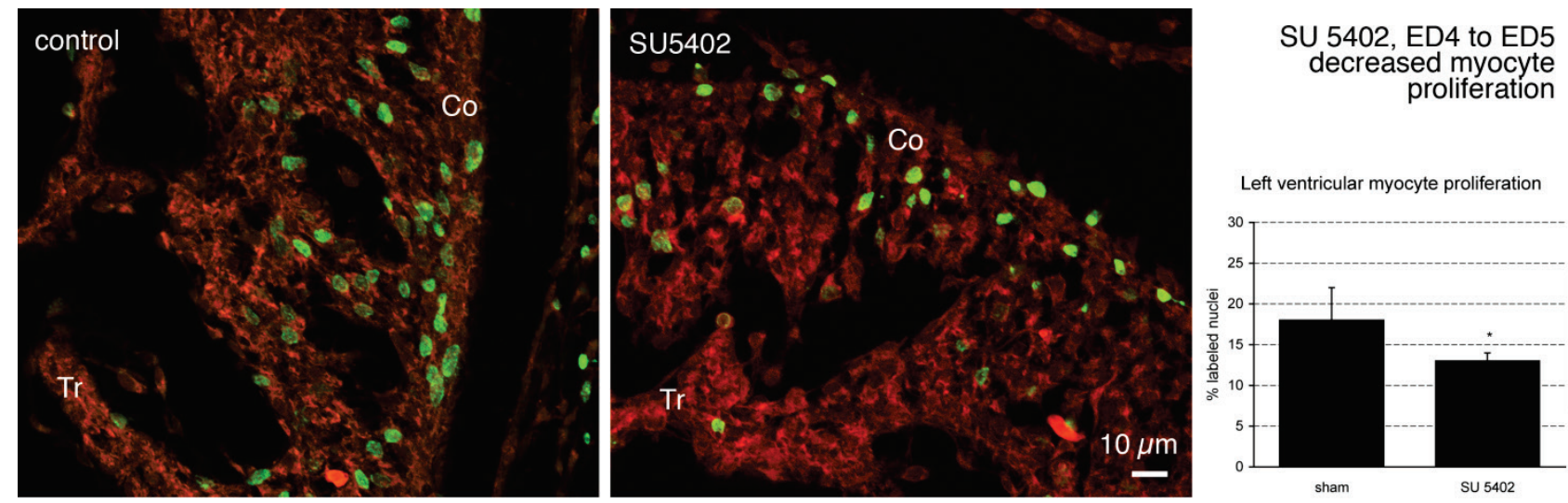

SU 5402, ED8 to ED9 $3 / 12$ treated hearts show subepicardial hemorrhage (arrows)
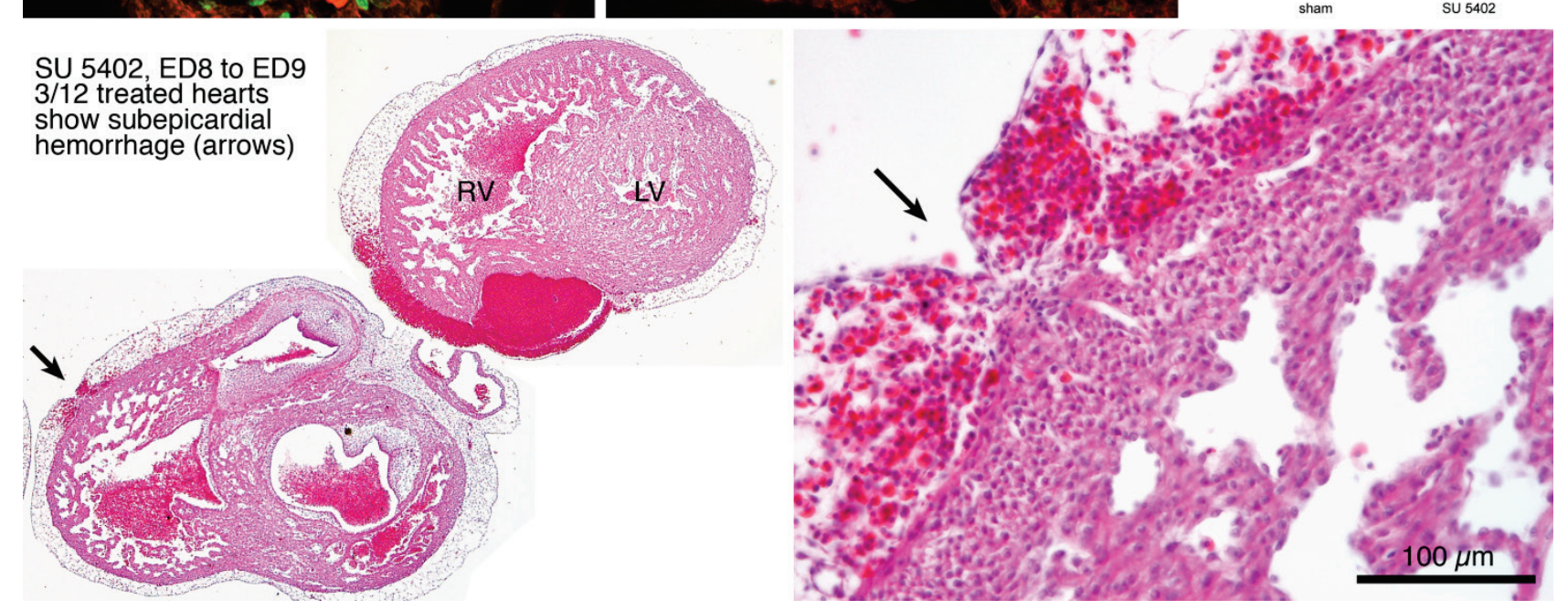

Fig. 4. Cardiac phenotype after inhibition with SU5402. Top row: decreased proliferation $24 \mathrm{~h}$ after intrathoracic administration $(6.25 \mu \mathrm{g}$ dose in $1 \mu \mathrm{l}$ DMSO) at ED4. Bromodeoxyuridine labeling (green) is notably decreased; tissue autofluorescence in red. Co, compact zone; Tr, trabeculae. Scale bar $10 \mu \mathrm{m}$. Quantification is shown in the bar chart on the right; $*$ p $<0.05$. Bottom: subepicardial hemorrhages observed $24 \mathrm{~h}$ after global administration ( $25 \mu \mathrm{g}$ of SU5402 intraamniotically) at ED8. LV, left ventricle; $\mathrm{RV}$, right ventricle. Scale bar $100 \mu \mathrm{m}$.

\section{Discussion}

There are several ways of targeted increase of FGF2 in the embryo, one of the proven ones being localized injection of FGF2-expressing adenovirus (de Almeida and Sedmera 2009). Detailed morphological re-examination of FGF2-expressing adenovirus injected hearts from that study revealed no difference in normal myocardial architecture despite increased levels of myocyte proliferation. There was no difference in capillary density or coronary artery anomalies (Nanka et al. 2009), suggesting that the extra FGF2 resulted in coordinated proliferation of both cardiomyocytes and capillaries, similar to earlier findings of Tomanek et al. (1999) in the conotruncal banding model. In this context, we were initially surprised by the finding of no change or 
actual decrease of the FGF2 protein in the myocardium of the banded hearts, which are known to compensate the pressure overload by myocyte hyperplasia (Clark et al. 1989). These findings were explained by further evidence from RT-PCR showing an increase transcription at the early time points after banding ( 24 and $36 \mathrm{~h}$ ), and ELISA assay showing that the "missing" protein was most likely released into blood by increased myocyte stretching. We chose the RT-PCR approach instead of relying on in situ hybridization studies performed by Mikawa lab and others (Speir et al. 1992), as it is often difficult to quantify the color reaction product in whole mount in situ (Hall et al. 2004). It is also possible that the extra FGF2 synthesized by the myocytes in response to increased stress already saturated the receptors, and therefore increased the signaling cascade to the maximum before being released from the heart to circulation. This would explain that the only effects on proliferation and vasculogenesis in the CTB model were observed in the heart, and not elsewhere in the embryo (Tomanek et al. 1999).

We did not emphasize the differences in response between the left and right ventricle, since during preseptation stages of heart development, both ventricles operate in parallel. However, it is interesting to note that the right ventricular response in by proliferation increase lagged behind the left ventricle (Fig. 2 and Supplemental Fig. 1). This delay corresponds well to previously increased delay in compact layer thickening observed both naturally (Sedmera et al. 2000) and after CTB (Sedmera et al. 1999b), as well as to about 2-day delay in right ventricular maturation detected by gene chip array (Krejci et al. 2012).

Given the widespread expression of FGFs in the developing embryo, the increased amounts of FGF2 in the serum could arise from multiple sources. It is possible that potential restriction of blood supply to the embryo induced by conotruncal banding could lead to tissue hypoxia that might lead to increased production of FGF2 to increase vascularization - a similar mechanism operating, e.g. during normal coronary artery development in response to myocardial hypoxia (Tomanek et al. 1996, 1998, 2008). This concept is supported by finding of augmented extent of hypoxic regions detected by hypoxyprobe in the thickened ventricular wall $72 \mathrm{~h}$ after banding (Fig. 1). To exclude the extracardiac sources, RT-PCR was performed on whole embryos from which the hearts were already extracted. No difference from sham-operated embryos was detected at the $48 \mathrm{~h}$ interval, but there was a significant increase at the $36 \mathrm{~h}$ time point. These findings are consistent with the previous reports finding increased myocardial mass at 3 days after CTB (Tomanek et al. 1999), and increase in ventricular wall thickness was observed after 2 days in the left ventricle and 3 days in the right ventricle (Sedmera et al. 1999b).

There is previous evidence that myocardial stretch induces FGF release in developing chick hearts (Aranega et al. 1998). These investigators observed, using SDS-PAGE and Western blotting, that perfusion of isolated embryonic hearts at Stage 25 and 33 at both normal and increased pressure resulted in release of FGF2 protein into medium (A. Aránega, personal communication).

Increased myocyte proliferation in the pressure overload model was first demonstrated biochemically (Clark et al. 1989) and then confirmed on cellular level by label dilution data, which showed an increase in the compact layer and no changes in the conduction system (Sedmera et al. 2005), showing that not all embryonic cardiomyocytes are load-sensitive. The present study shows that the window of maximal proliferative response occurs at $48 \mathrm{~h}$, with no difference at 24 or $72 \mathrm{~h}$. These trends are paralleled by semiquantitative immunohistochemical data (Fig. 2). Increased myocyte proliferation is matched by increased vasculogenesis, resulting in a constant ratio between myocytes and vascular elements in the CTB model of enhanced cardiac growth (Tomanek et al. 1999). FGF2 down regulation was also observed in other models of embryonic heart remodeling based upon decreased proliferation, such as left ventricular hypoplasia (Sedmera et al. 1999b, Tobita et al. 2005), and pacing-induced wall thinning (Sedmera et al. 1999a). These results by no means rule out concomitant involvement of other growth factors, implicated in control of myocardial proliferation such as PDGF (Jedlicka et al. 1991, Kang et al. 2008) or IGF (Li et al. 2011).

Previous studies have demonstrated that in addition to paracrine activity on nearby cells, FGF2 is also capable to act at distance in an autocrine manner, as in regulation of blood pressure that is disturbed in FGF2 null mice (Zhou et al. 1998). FGF2 acts on numerous cell types, and its activity results in coordinated growth such as in the case of myocardium, and its coronary blood supply (Pennisi et al. 2003, Lavine et al. 2008).

Other FGF family members are known to be expressed in the developing heart (Kelly et al. 2001), 
however, only one FGF receptor, FGFR1, was reported to be expressed in the heart at the stages studied. A recent review (Lavine and Ornitz 2009) detailed the contribution of FGF1, FGF2, FGF16, and FGF20 in myocardial proliferation and coronary vasculature together with providing a model involving the receptors, epicardial signaling and upstream regulation by retinoic acid. Analysis of myocardial-specific mouse knockout models for FGFR1 and 2 revealed the essential roles of the above mentioned FGFs for both cardiomyocyte proliferation and coronary vascular formation and growth (Lavine et al. 2005). We have therefore focused on receptor inhibition to knock down all the FGF signaling in the heart. Global inhibition of FGF signaling was very toxic for the early embryos, similar to poorly tolerated systemic FGF2 administration (de Almeida and Sedmera 2009). It is possible that embryonic FGF2 toxicity was related to vascular effects or inhibition of vasculogenesis, limiting direct use to local administration via injections or microbeads (Franciosi et al. 2000, Lavine et al. 2008). Subepicardial hemorrhages (Fig. 4), and hemorrhages into cartilaginous skeletal elements of the developing limbs (Supplemental Fig. 2) support the idea that FGF2 administration causes vascular toxicity. We were able to overcome this systemic toxicity by localized administration of the inhibitor SU5402 into the pericardial cavity, and demonstrated that indeed it resulted in a significant decrease by myocyte proliferation, as expected (Fig. 4). It would be interesting to test whether blocking of FGF signaling would attenuate the CTB-induced spike of proliferation; however, combination of these two protocols is impractical, since both carry considerable mortality, and intrathoracic injection at ED5-6 is rather challenging because of embryo position deep in the yolk. Furthermore, the likely result would be embryonic death, since the increased cardiac mass in response to CTB is considered an adaptation necessary for increased cardiac performance (to overcome the obstruction) and survival, which would make the interpretation difficult and inconclusive.

FGF signaling is also prominent in limb development, where its expression patterns correlate chiefly with the proximo-distal growth and mediate the inductive activity of the apical ectodermal ridge in the mesenchyme in the progress zone (Peters et al. 1992).
Our results of the inhibition experiment confirmed the significance of FGF signaling cascade in this region by documenting decrease of proliferation, but also distinct hitherto unpublished effect on vasculogenesis in this area. We recognize that these effects might not be entirely specific, as SU5402 also inhibits other receptor kinase activity such as PDGFR and VEGR2. Newly forming delicate vascular network is probably highly sensitive to perturbations of growth factor signaling, forming the basis of using such inhibitors as potential anticancer drugs but also cautioning about their embryotoxic effects. To exclude possible direct toxic effects of SU5402, we performed immunostaining for active caspase-3, an established marker for apoptosis, on sister sections. We did not observe any positivity in the heart or limb tips, which was further corroborated by lack of nuclear pyknosis in the nuclear counterstaining (data not shown).

In conclusion, it appears that FGF signaling is important in controlling embryonic growth and vasculogenesis and that this signaling cascade is part of the self-regulatory loop in cardiac adaptations to hemodynamic challenges such as increased pressure loading.

\section{Conflict of Interest}

There is no conflict of interest.

\section{Acknowledgements}

We would like to express our sincere thanks to Prof. Christophe Reymond (Universite de Lausanne) for performing the Western blot experiment, Ms. Mauricette Kapt (Universite de Lausanne) and Ms. Angela deAlmeida (Medical University of South Carolina) for excellent histological support, Dr. Ning Zhang (Medical University of South Carolina) for unbiased quantification of myocardial FGF levels, Ms. Alena Kvasilova (Charles University in Prague) for histological assistance, and Prof. Amelia Aranega (University of Jaen, Spain) for discussion of the FGF2 release from stretched chick embryonic hearts. Prof. Paul E. Mozdziak (NC State University) is acknowledged for language revision. Supported by Ministry of Education PRVOUK P35/LF1/5, Academy of Sciences AV0Z50110509, Charles University UNCE 204013, and Grant Agency of the Czech Republic P302/11/1308 and 16-02972S. 


\section{References}

ARANEGA A, VELEZ C, MARTINEZ-LARA E, LOPEZ-ARCO M, AVAREZ L, THOMPSON RP: Stretch-induced release of b-FGF from developing chick heart. In: ESC Working Group on Developmental Anatomy and Pathology. Malaga, Spain, 1998. (Abstract.)

CHEN TH, CHANG TC, KANG JO, CHOUDHARY B, MAKITA T, TRAN CM, BURCH JB, EID H, SUCOV HM: Epicardial induction of fetal cardiomyocyte proliferation via a retinoic acid-inducible trophic factor. Dev Biol 250: 198-207, 2002.

CLARK EB, HU N, FROMMELT P, VANDEKIEFT GK, DUMMETT JL, TOMANEK RJ: Effect of increased pressure on ventricular growth in stage 21 chick embryos. Am J Physiol 257: H55-H61, 1989.

CLARKE MS, CALDWELL RW, CHIAO H, MIYAKE K, MCNEIL PL: Contraction-induced cell wounding and release of fibroblast growth factor in heart. Circ Res 76: 927-934, 1995.

DE ALMEIDA A, SEDMERA D: Fibroblast Growth Factor-2 regulates proliferation of cardiac myocytes in normal and hypoplastic left ventricles in the developing chick. Cardiol Young 19: 159-169, 2009.

DEMIROGLU A, STEER EJ, HEATH C, TAYLOR K, BENTLEY M, ALLEN SL, KODURU P, BRODY JP, HAWSON G, RODWELL R, DOODY ML, CARNICERO F, REITER A, GOLDMAN JM, MELO JV, CROSS NC: The $t(8 ; 22)$ in chronic myeloid leukemia fuses BCR to FGFR1: transforming activity and specific inhibition of FGFR1 fusion proteins. Blood 98: 3778-3783, 2001.

EBERT AD, LAUSSMANN M, WEGEHINGEL S, KADERALI L, ERFLE H, REICHERT J, LECHNER J, BEER HD, PEPPERKOK R, NICKEL W: Tec-kinase-mediated phosphorylation of fibroblast growth factor 2 is essential for unconventional secretion. Traffic 11: 813-826, 2010.

FARRELL MJ, BURCH JL, WALLIS K, ROWLEY L, KUMISKI D, STADT H, GODT RE, CREAZZO TL, KIRBY ML: FGF-8 in the ventral pharynx alters development of myocardial calcium transients after neural crest ablation. J Clin Invest 107: 1509-1517, 2001.

FRANCIOSI JP, BOLENDER DL, LOUGH J, KOLESARI GL: FGF-2-induced imbalance in early embryonic heart cell proliferation: a potential cause of late cardiovascular anomalies. Teratology 62: 189-194, 2000.

GIBBY KA, MCDONNELL K, SCHMIDT MO, WELLSTEIN A: A distinct role for secreted fibroblast growth factorbinding proteins in development. Proc Natl Acad Sci U S A 106: 8585-8590, 2009.

HALL CE, HURTADO R, HEWETT KW, SHULIMOVICH M, POMA CP, RECKOVA M, JUSTUS C, PENNISI DJ, TOBITA K, SEDMERA D, GOURDIE RG, MIKAWA T: Hemodynamic-dependent patterning of endothelin converting enzyme 1 expression and differentiation of impulse-conducting Purkinje fibers in the embryonic heart. Development 131: 581-592, 2004.

JEDLICKA S, FINKELSTEIN JN, PAULHAMUS LA, CLARK EB: Increased PDGF-like protein in banded embryonic ventricle. Pediatr Res 29: 19A, 1991.

JELINEK R, PETERKA M, RYCHTER Z: Chick embryotoxicity screening test--130 substances tested. Indian J Exp Biol 23: 588-595, 1985.

KANG J, GU Y, LI P, JOHNSON BL, SUCOV HM, THOMAS PS: PDGF-A as an epicardial mitogen during heart development. Dev Dyn 237: 692-701, 2008.

KARDAMI E, LIU L, KISHORE S, PASUMARTHI B, DOBLE BW, CATTINI PA: Regulation of basic fibroblast growth factor (bFGF) and FGF receptors in the heart. Ann N Y Acad Sci 752: 353-369, 1995.

KELLY RG, BROWN NA, BUCKINGHAM ME: The arterial pole of the mouse heart forms from Fgf10-expressing cells in pharyngeal mesoderm. Dev Cell 1: 435-440, 2001.

KREJCI E, PESEVSKI Z, DEALMEIDA AC, MRUG M, FRESCO VM, ARGRAVES WS, BARTH JL, CUI X, SEDMERA D: Microarray analysis of normal and abnormal chick ventricular myocardial development. Physiol Res 61 (Suppl 1): S137-S144, 2012.

LAVINE KJ, ORNITZ DM: Shared circuitry: developmental signaling cascades regulate both embryonic and adult coronary vasculature. Circ Res 104: 159-169, 2009.

LAVINE KJ, YU K, WHITE AC, ZHANG X, SMITH C, PARTANEN J, ORNITZ DM: Endocardial and epicardial derived FGF signals regulate myocardial proliferation and differentiation in vivo. Dev Cell 8: 85-95, 2005. 
LAVINE KJ, SCHMID GJ, SMITH CS, ORNITZ DM: Novel tool to suppress cell proliferation in vivo demonstrates that myocardial and coronary vascular growth represent distinct developmental programs. Dev Dyn 237 : 713-724, 2008.

LI P, CAVALLERO S, GU Y, CHEN TH, HUGHES J, HASSAN AB, BRUNING JC, PASHMFOROUSH M, SUCOV HM: IGF signaling directs ventricular cardiomyocyte proliferation during embryonic heart development. Development 138: 1795-1805, 2011.

MARQUES SR, LEE Y, POSS KD, YELON D: Reiterative roles for FGF signaling in the establishment of size and proportion of the zebrafish heart. Dev Biol 321: 397-406, 2008.

MIKAWA T: Retroviral targeting of FGF and FGFR in cardiomyocytes and coronary vascular cells during heart development. Ann N Y Acad Sci 752: 506-516, 1995.

MIMA T, UENO H, FISCHMAN DA, WILLIAMS LT, MIKAWA T: Fibroblast growth factor receptor is required for in vivo cardiac myocyte proliferation at early embryonic stages of heart development. Proc Natl Acad Sci US A 92: 467-471, 1995.

NANKA O, VALASEK P, DVORAKOVA M, GRIM M: Experimental hypoxia and embryonic angiogenesis. Dev Dyn 235: 723-733, 2006.

NANKA O, KRIZOVA P, FIKRLE M, TUMA M, BLAHA M, GRIM M, SEDMERA D: Abnormal myocardial and coronary vasculature development in experimental hypoxia. Anat Rec (Hoboken) 291: 1187-1199, 2008.

NANKA O, PETROVOVA E, FIKRLE M, DE ALMEIDA A, SEDMERA D: Regulation of embryonic cardiac wall growth and vascularization by FGF-2. FASEB J 23: Abstract 642.643, 2009.

PENNISI DJ, BALLARD VL, MIKAWA T: Epicardium is required for the full rate of myocyte proliferation and levels of expression of myocyte mitogenic factors FGF2 and its receptor, FGFR-1, but not for transmural myocardial patterning in the embryonic chick heart. Dev Dyn 228: 161-172, 2003.

PETERS KG, WERNER S, CHEN G, WILLIAMS LT: Two FGF receptor genes are differentially expressed in epithelial and mesenchymal tissues during limb formation and organogenesis in the mouse. Development 114: 233-243, 1992.

SATO A, SCHOLL AM, KUHN EN, STADT HA, DECKER JR, PEGRAM K, HUTSON MR, KIRBY ML: FGF8 signaling is chemotactic for cardiac neural crest cells. Dev Biol 354: 18-30, 2011.

SEDMERA D, PEXIEDER T, HU N, CLARK EB: Developmental changes in the myocardial architecture of the chick. Anat Rec 248: 421-432, 1997.

SEDMERA D, GROBETY M, REYMOND C, BAEHLER P, KUCERA P, KAPPENBERGER L: Pacing-induced ventricular remodeling in the chick embryonic heart. Pediatr Res 45: 845-852, 1999a.

SEDMERA D, PEXIEDER T, RYCHTEROVA V, HU N, CLARK EB: Remodeling of chick embryonic ventricular myoarchitecture under experimentally changed loading conditions. Anat Rec 254: 238-252, $1999 \mathrm{~b}$.

SEDMERA D, PEXIEDER T, VUILLEMIN M, THOMPSON RP, ANDERSON RH: Developmental patterning of the myocardium. Anat Rec 258: 319-337, 2000.

SEDMERA D, HU N, WEISS KM, KELLER BB, DENSLOW S, THOMPSON RP: Cellular changes in experimental left heart hypoplasia. Anat Rec 267: 137-145, 2002.

SEDMERA D, KUCERA P, KOLAR F, THOMPSON RP: Proliferative responses to myocardial remodeling in the developing heart. In: Cardiovascular Development and Congenital Malformations: Molecular and Genetic Mechanisms. ARTMAN M, BENSON DW, SRIVASTAVA D, NAKAZAWA M (eds), Blackwell Publishing, Malden, 2005, pp 47-51.

SHEIKH F, FANDRICH RR, KARDAMI E, CATTINI PA: Overexpression of long or short FGFR-1 results in FGF-2mediated proliferation in neonatal cardiac myocyte cultures. Cardiovasc Res 42: 696-705, 1999.

SPEIR E, TANNER V, GONZALEZ AM, FARRIS J, BAIRD A, CASSCELLS W: Acidic and basic fibroblast growth factors in adult rat heart myocytes. Localization, regulation in culture, and effects on DNA synthesis. Circ Res 71: 251-259, 1992.

SUGI Y, SASSE J, LOUGH J: Inhibition of precardiac mesoderm cell proliferation by antisense oligodeoxynucleotide complementary to fibroblast growth factor-2 (FGF- 2). Dev Biol 157: 28-37, 1993.

SUGI Y, SASSE J, BARRON M, LOUGH J: Developmental expression of fibroblast growth factor receptor-1 (cek-1; flg) during heart development. Dev Dyn 202: 115-125, 1995. 
TOBITA K, GARRISON JB, LI JJ, TINNEY JP, KELLER BB: Three-dimensional myofiber architecture of the embryonic left ventricle during normal development and altered mechanical loads. Anat Rec A Discov Mol Cell Evol Biol 283: 193-201, 2005.

TOMANEK RJ, HAUNG L, SUVARNA PR, O'BRIEN LC, RATAJSKA A, SANDRA A: Coronary vascularization during development in the rat and its relationship to basic fibroblast growth factor. Cardiovasc Res 31 (Spec No): E116-E126, 1996.

TOMANEK RJ, LOTUN K, CLARK EB, SUVARNA PR, HU N: VEGF and bFGF stimulate myocardial vascularization in embryonic chick. Am J Physiol 274: H1620-H1626, 1998.

TOMANEK RJ, HU N, PHAN B, CLARK EB: Rate of coronary vascularization during embryonic chicken development is influenced by the rate of myocardial growth. Cardiovasc Res 41: 663-671, 1999.

TOMANEK RJ, HANSEN HK, CHRISTENSEN LP: Temporally expressed PDGF and FGF-2 regulate embryonic coronary artery formation and growth. Arterioscler Thromb Vasc Biol 28: 1237-1243, 2008.

TORLOPP A, SCHLUETER J, BRAND T: Role of fibroblast growth factor signaling during proepicardium formation in the chick embryo. Dev Dyn 239: 2393-2403, 2011.

VEGA-HERNANDEZ M, KOVACS A, DE LANGHE S, ORNITZ DM: FGF10/FGFR2b signaling is essential for cardiac fibroblast development and growth of the myocardium. Development 138: 3331-3340, 2011.

ZHOU M, SUTLIFF RL, PAUL RJ, LORENZ JN, HOYING JB, HAUDENSCHILD CC, YIN M, COFFIN JD, KONG L, KRANIAS EG, LUO W, BOIVIN GP, DUFFY JJ, PAWLOWSKI SA, DOETSCHMAN T: Fibroblast growth factor 2 control of vascular tone. Nat Med 4: 201-207, 1998.

ZHU X, SASSE J, LOUGH J: Evidence that FGF receptor signaling is necessary for endoderm-regulated development of precardiac mesoderm. Mech Ageing Dev 108: 77-85, 1999. 